\title{
Petroleum and Refining Engineering- Brief Review on Few Key Aspects
}

\author{
Dr. Sunil Jayant Kulkarni \\ Datta Meghe College of Engineering, Airoli, Navi Mumbai, Maharashtra, India
}

*Corresponding Author: Dr. Sunil Jayant Kulkarni, Datta Meghe College of Engineering, Airoli, Navi Mumbai, Maharashtra, India

\begin{abstract}
The petroleum industry is facing challenges in terms of cost, safety and environmental regulations. The demand for energy is ever increasing. The crude oil exploration and refining contribute major part of economy. Increased industrialization calls for more efficient methods for oil exploration, petroleum refining and re-refining. Many times, the oil exploration and consumption is deciding factor for growth. Various aspects such as catalyst cracking, sludge handling, gas recovery are being studied for optimization and effluent management. Many investigators have carried out investigations on these aspects. It is very important to have effective methods for the optimization of the reactions carried out in these industries. The increased cost and depleting resources highlight the need for enhanced oil recovery. Material substances, processes or circumstances which pose threat to health and well being of workers in any occupation are termed as occupational hazards. The present review provides brief insight into research and studies of these key aspects of petroleum and refining engineering.
\end{abstract}

Keywords: Recovery, accumulation, cracking, sorbents, organic matter, concentration.

\section{INTRODUCTION}

The demand for energy is ever increasing. The crude oil exploration and refining contribute major part of economy. Increased industrialization calls for more efficient methods for oil exploration, petroleum refining and re-refining. The key aspects in petroleum and refining engineering are catalysis, oil recovery and treatment [1-5]. Many investigators have carried out investigations on these aspects. It is very important to have effective methods for the optimization of the reaction carried out in these industries. This can save some cost and add to economy. The catalyst cracking is important part of these petroleum processes. The key to economical operation of the process is effective and efficient use of catalyst in desulphurization. In petroleum and refining industry, efficient oil exploration is very important aspect. The increased cost and depleting resources highlight need for enhanced oil recovery [6]. The current review also summarizes important research activities on enhanced oil recovery. There are many methods for treating petroleum wastewater. These can be used with more or less modifications [7-9]. This review also summarizes research and studies on petroleum wastewater and sludge treatment with emphasis on oil separation. Material substances, processes or circumstances which pose threat to health and well being of workers in any occupation are termed as occupational hazards [10-14].The health and safety of worker is most important. The safety and hazards in petroleum and refining industries is investigated by various researchers. Research and studies on safety and hazards in petroleum industries are summarized in last part of the article.

\section{ENHANCED OIL ReCovery- A SOUght AfTer Cost Reduction Method}

Many methods such as water alternating gas (WAG) or simultaneous water alternating gas(SWAG) are being implemented as per Alagorni et.al [15]. According to their studies, these methods have still some problems encountered by EOR engineers. In their investigations, they used nitrogen injection as one of the enhanced oil recovery methods. They counted many advantages of nitrogen such as such as availability, its noncorrosive and inert gas nature, friendliness to environment. Also it is less compressible than $\mathrm{CO}_{2}$. Factors affecting the recovery of this residual oil were studied by Vesna et.al. [16]. According to their studies, oil recovery methods are classified as thermal methods, chemical methods, miscible/immiscible gas injection methods and other methods. The basis for their studies 
and justifying application of new technologies for crude oil is their price. A natural gas flooding or water flooding are used to maintain pressure in secondary recovery section. Enhanced oil recovery processes and their advancements were discussed by Romero-Zeron [17]. According to him there is renewed interest on research and development of EOR processes. By using these advanced oil recovery methods, it was possible to target significant volumes of oil accumulations. According to him, in achieving EOR targets, a synergistic approach among EOR processes can be a great help. Thermal pyrolysis for recovery of hydrocarbon liquid from waste high density polyethylene was studied by Kumar and Singh [18]. The material for pyrolysis used by them was waste high-density polyethylene (HDPE) plastic. They also optimized the liquid product yield at a temperature range of $400^{\circ} \mathrm{C}$ to $550^{\circ} \mathrm{C}$. Their studies indicated that the major product of the pyrolysis was oily liquid below 450 degree Celsius. An investigation on recovery of hydrocarbons with emphasis on induced seismicity and hydraulic fracturing was carried out by Davies et.al. [19]. In their work, they proposed fluid pulse pathways including steps like directly from the wellbore. They used them through new stimulated hydraulic fractures, through pre-existing fractures and minor faults and through the pore network of permeable beds or along bedding planes. They observed that low volumes of fluid and short pumping times were a relatively benign mechanism. According to investigation carried out by Gudina et.al., on enhance oil recovery in laboratory sand-pack columns, the additional oil recoveries ranged from 6 to 24\%. [20]. They also tried to retrieve the oil from mature reservoirs. Measures to reduce emissions of VOCs during loading and unloading of ships were studied by Rudd and Hill [21]. They observed that VOC emissions from the loading of petroleum product are 0.07 percent of total VOC emission. According to them crude loading contributes 0.8 percent of total VOC. Their studies indicated that ship driven activities such as loading, unloading, ballasting and transportation contributes to VOC. According to them, for VOC control, methods such as reducing volatility, vapour balancing, thermal oxidation, absorption, adsorption, membrane separation and cryogenic condensation are useful.

\section{Catalysts- Core of the Process}

An investigation on modeling and simulation of continuous catalytic regeneration process(CCR) was carried out by Saidi et.al. According to them, CCR process is very important in petrochemical and petroleum refining for octane improvement and production of aromatic feedstock[22]. In their studies, they lumped the parameters in to $\mathrm{C}_{1}, \mathrm{C}_{2}, \mathrm{C}_{3}, \mathrm{C}_{4}, \mathrm{C}_{5}, \mathrm{p}$ (paraffin), $\mathrm{n}$ (naphthene), a (aromatic) and $\mathrm{H}_{2}$. According to studies carried out by Marcilly, zeolitic catalysts contribute substantially to refining and petrochemicals [23]. Also he pointed that development of any new process always comes up against the unavoidable need to be profitable and competitive. An investigation on petroleum refining by using platinum catalyst was carried out by Curry [24].According to him, catalytic refining is gaing importance as it enables improvement in octane rating. Emam noted that clays are used in petroleum industry for number of processes like catalytic cracking, hydrocracking, reforming, isomerization, hydrogenation, alkylation, etc. According to his studies, kaolin and montmorillonite are the most important clays used[25]. Kovin et.al. felt a need to modernize Russian refineries based on catalytic cracking with maximum application of domestic technologies. It can ensure increased high-quality fuels production in shortest time with relatively low capital expenditures[26].

\section{TREATMENT- TOWARDS RESPONSIBLE ENGINEERING}

Igunnu and Chen evaluated current technologies for the management of produced water[27]. Various treatment technologies used in produced water treatment were discussed by them. These technologies include membrane filtration technology, thermal technologies, biological aerated filters, electrode alysis/electro dialysis reversal, freeze thaw evaporation etc. They pointed out two key drawbacks of membrane technologies. These were membrane fouling and secondary waste generation. In the future management of produced water, according to them, macro-porous polymer extraction technology (MPPPE) technology can compete. An investigation on used of petroleum cuts as solvent for treatment of waste sludge was carried out by Naggar [28].Their work indicated that the maximum oil recovery obtained varied from $80-97 \%$. It depended on the amount of oil within the sludge and the solvent efficiency used for extraction. Hayes et.al. presented results of integrated electro dialysis pilot unit[29]. They found that 99.5 percent of oil and grease from effluent can be removed by this technology. According to them, processes like API separator, deep bed filter, hydro cyclone, induced gas flotation and ultra-filtration have huge potential. According to studies carried out by Helmy and Kardena, almost $85 \%$ removal total petroleum hydrocarbon (TPH) of oil and grease can be 
accomplished by using bioemulsifier[30]. Advanced oxidation method was used for sludge treatment by Aljubourya et.al.[31]. Comparison of various oxidation processes was carried out by them. According to their studies, Fenton process was more efficient that solar photo catalysis $-\mathrm{TiO}_{2}$ process. The studies also indicated that solar oxidation process was better for acidic conditions. They also found that $\mathrm{pH}$ and $\mathrm{H}_{2} \mathrm{O}_{2}$ concentration affected the solar oxidation. Characterization and treatment of petroleum sludge was carried out by Asia et.al.[32]. They found that the sludge had high electrical conductivity. This was indicator of the fact that the sludge can potentially be treated by physicochemical method of coagulation and flocculation. According to studies carried out by Kumar and Raj, there is possibility of use of microwave for treating oil sludge from petroleum industries [33]. Their studies indicated that less time, better efficiency and better oil recovery contributes to the effectiveness of this method in positive manner.

\section{SAFETY - Human Angle in Process}

Eyayo investigated occupational health hazards among oil industry workers [34]. According to him, one should identify occupational health hazard in addition to occupational safety hazard. He classified the hazards as physical health hazard, chemical health hazard, biological health hazard, mechanical/ergonomic health hazard and psychosocial health hazard. He emphasized that health effect management process was an element in occupational health and safety management system (OHSMS) amongst others. Witter et. al. pointed out that the occupational hazard is major issue in oil and gas extraction industry[35].Their studies indicated that fatality rate in this industry were 2.5 times more than construction industry and 7 times more than general industry. He emphasized the need to have collaborative approach between educational firms and industries. Bachmann et.al. felt the need to remove sulphur metal, nitrogen as well as undesirable organic compounds from the crude[36]. Health risk assessment for exposure to benzene in petroleum refinery environments was carried out by Edokpolo et.al.[37]. Cumulative probability distributions (CPD) plots were prepared by them. In their work, they collated the exposure data into four scenarios from petroleum refinery environments. Also slope factor and overall risk probability (ORP) methods for evaluation of the excess cancer risk (CR) for lifetime exposure to benzene were employed by them. According to Khan, operations and processes in petroleum industries are hazardous, due to properties of the petroleum products and raw materials [38]. The important contributors are volatile, flammable and inflammatory. He emphasized that it is important to understand the properties, energy associated with compounds and thermal stability.

\section{CONClusion}

Studies indicate that that synergistic approach among EOR processes can be a great help in achieving EOR targets. From the second section of the review, it can be concluded that the use of proper catalyst and flue gas treatment are two important aspects for effective and environment friendly operation of petroleum and refinery units. Regarding the sludge treatment, it can be seen from the review that the methods such as bioremediation, oxidation method, stabilization/solidification, incineration, froth flotation method, ultrasonic irradiation, electro kinetic method, centrifugation method, microwave heating method, cyclone, ultra high temperature gasification, solvent extraction, manual cleaning and incineration can be employed according to the requirements. The last section in the paper points out that the occupational and hazard is major issue in oil and gas extraction industry. Many investigators have emphasized need to have collaborative approach between educational firms and industries.

\section{REFERENCES}

[1] Pia M. Berglund and Göran Petersson (1990) Hazardous petrol hydrocarbons from refueling with and without vapour recovery. Sci. Total Environ. 91: 49-57.

[2] Sunil Jayant Kulkarni(2016) A Review on Petroleum Refining and Petrochemical Processes with Special Emphasis on Catalysts and Flue Gas Treatment Technology. International Journal of Petroleum and Petrochemical Engineering 2(1):1-5.

[3] Hardikkumar V. Shrimali (2015) Developments in Enhanced Oil Recovery Technologies-A Review. International Journal of Research in Advent Technology 3(6):1-6.

[4] Eduardo J. Gudina, Jorge F.B. Pereir, Rita Costa, Joao A.P. Coutinho, Jose. Teixeir, Lígia R. Rodrigues(2013) Biosurfactant-producing and oil-degrading Bacillus subtilis strainsenhance oil recovery in laboratory sand-pack columns. Journal of Hazardous Materials 261: 106- 113.

[5] Sunil J Kulkarni(2017) An Insight into Research and Studies on Enhanced Oil Recovery (EOR) in Petroleum Industries. International Journal of Petroleum and Petrochemical Engineering 3(2):1-4. 
[6] Sunil Jayant Kulkarni(2017) An Insight into Oil and Grease Removal from Wastewater from Petroleum and Refinery Industries. International Journal of Petroleum and Petrochemical Engineering 3(2):PP. 1-4

[7] Sunil J. Kulkarni, Ajaygiri K. Goswami(2014) Applications and Advancements in Treatment of Waste Water by Membrane Technology- A Review. International Journal of Engineering Sciences and Research Technology 3(9):446-450.

[8] Sunil Jayant Kulkarni(2016) An Insight into Studies and Research on Wastewater and Sludge Treatment in Petroleum Industries and Refineries with Emphasis on Oil Separation. International Journal of Petroleum and Petrochemical Engineering 2(2): 4-7

[9] Sunil J. Kulkarni(2014) Modeling for Adsorption Columns for Wastewater Treatment: a Review. International Journal of Innovative Research in Engineering \& Multidisciplinary Physical Sciences 2(2):711.

[10] Sunil Jayant Kulkarni, Ajaygiri Kamalgiri Goswami(2015) A Review on Wastewater Treatment for Petroleum Industries and Refineries. International Journal of Scientific Research in Science, Engineering and Technology. (1)3: 280-283.

[11] Ione L. Taylor(2004) Methods of Exploration and Production of Petroleum Resources. Geology 5:1-7.

[12] Toshi H. Arimura Kazuyuki Iwata(2010) Measures to Protect the Environment and Conserve Energy Taken by the United States and Japan: Review of Quantitative Analysis. Far eastern studies 9:65-87.

[13] Takele Tadesse(2004) Solid Waste management. University of Gondar In collaboration with the Ethiopia Public Health Training Initiative, The Carter Center, The Ethiopia Ministry of Health, and the Ethiopia Ministry of Education 1:1-120.

[14] Sunil Jayant Kulkarni(2017) Safety and Hazards in Petroleum Industries: Research, Studies and Surveys. International Journal of Petroleum and Petrochemical Engineering 3(1):31-34.

[15] Abubaker H. Alagorni, Zulkefli Bin Yaacob, and Abdurahman H. Nour(2015) An Overview of Oil Production Stages: Enhanced Oil Recovery Techniques and Nitrogen Injection. International Journal of Environmental Science and Development 6(9):693-702.

[16] Karovic Maricic Vesna, LekovicBranko, Danilovic Dusan(2014). Factors Influencing Successful Implementation of Enhanced Oil Recovery Projects. Underground Mining Engineering 25: 41-50.

[17] Laura Romero-Zeron(2012)Advances in Enhanced Oil Recovery Processes. www.intechopen.com 1:3-44.

[18] Sachin Kumar and R. K. Singh(2011) Recovery Of Hydrocarbon Liquid From Waste High Density Polyethylene By Thermal Pyrolysis. Brazilian Journal of Chemical Engineering. 28(4): 659 - 667.

[19] Richard Davies, Gillian Foulger, Annette Bindley, Peter Styles(2013) Induced seismicity and hydraulic fracturing for the recovery of Hydrocarbons, Marine and Petroleum Geology. 45: 171-185.

[20] Eduardo J. Gudina, Jorge F.B. Pereir, Rita Costa, Joao A.P. Coutinho,Jose. Teixeir, Lígia R. Rodrigues(2013) Biosurfactant-producing and oil-degrading Bacillus subtilis strainsenhance oil recovery in laboratory sand-pack columns. Journal of Hazardous Materials 261: 106-113.

[21] Howard J Rudd and Nikolas A Hill(2001) Measures to Reduce Emissions of VOCs during Loading and Unloading of Ships in the EU, AEA Technology Environment. AEAT/ENV/R/0469. 2:1-80.

[22] Majid Sa'idi, Navid Mostoufi, Rahmat Sotudehgharebagh(2011) Modeling and Simulation of Continuous Catalytic Regeneration (CCR)Process. International Journal of Applied Engineering Research, Dindigul 2(1):115-124.

[23] C. Marcilly(2001) Evolution Of Refining And Petrochemicals: What Is The Place of Zeolites. Oil \& Gas Science and Technology - Rev. IFP 56(5):499-514.

[24] . S. W. Curry(1957) Platinum Catalysts In Petroleum Refining. Platinum Metals Rev. 1(2): 38.

[25] Eman A. Emam(2013) Clays As Catalysts In Petroleum Refining Industry. ARPN Journal of Science And Technology 3(4):356-375.

[26] Kovin A.S., Sitdikova A.V., Rakhimov M.N.(2009) Catalytic Cracking Development And Its Role In Modern Russian Refinery. Oil and Gas Business 1:1-7.

[27] Ebenezer T. Igunnu And George Z. Chen(2012) Produced Water Treatment Technologies. International Journal Of Low-Carbon Technologies Oxford University Press 1:1-21.

[28] A. Y. El Naggar, E. A. Saad, A. T. Kandil and H. O. Elmoher(2010) Petroleum Cuts As Solvent Extractor For Oil Recovery From Petroleum Sludge. Journal of Petroleum Technology and Alternative Fuels 1(1):10-19.

[29] Tom Hayes, Dan Arthur(2004) Overview Of Emerging Produced Water Treatment Technologies. The 11th Annual International Petroleum Environmental Conference Albuquerque Hilton Hotel Albuquerque, NM , October 12-15:1-36.

[30] Qomarudin Helmy and Edwan Kardena(2015) Petroleum Oil and Gas Industry Waste Treatment; Common Practice in Indonesia. J Pet Environ Biotechnol. 6(5):1-7. 
[31] Dheeaa Al Deen Atallah Aljubourya, Puganeshwary Palaniandy, Hamidi Bin Abdul Aziz and Shaik Feroz(2015) Comparative Study Of Advanced Oxidation Processes To Treat Petroleum Wastewater. Hungarian Journal of Industry And Chemistry 43(2):97-101.

[32] Asia, I. O., Enweani, I. B. and Eguavoen I. O.(2006) Characterization And Treatment Of Sludge From The Petroleum Industry. African Journal of Biotechnology5(5):461-466.

[33] Bipin Kumar, Dr. Raj Mohan B.(2013) Petroleum Oily Sludge and The Prospects of Microwave for Its Remediation. International Journal of Engineering Research \& Technology 2(11):359- 370.

[34] Faith Eyayo(2014) Evaluation of Occupational Health Hazards among Oil Industry Workers: A Case Study of Refinery Workers. IOSR Journal of Environmental Science, Toxicology and Food Technology: 8(12), Ver. I (Dec. 2014):22-53.

[35] Roxana Z. Witter, LilianaTenney, Suzanne Clark, and Lee S. Newman(2014) Occupational Exposures in the Oil and Gas Extraction Industry: State of the Science and Research Recommendations. 2014 Wiley Periodicals, Inc.:1-10.

[36] Robert Thomas Bachmann, Anbu Clemensis Johnson, Robert G.J. Edyvean(2014) Biotechnology in the petroleum industry: An overview. International Biodeterioration and Biodegradation 86:225-237.

[37] Benjamin Edokpolo, Qiming Jimmy Yu and Des Connell(2015) Health Risk Assessment for Exposure to Benzene in Petroleum Refinery Environments. Int. J. Environ. Res. Public Health 1:595-610.

[38] A.A. Khan(1999) Risk Assessment in Petrochemical Industry. First International Seminar SAFE 99 on Safety and Fire Engineering. Kochin, India, November, 24-261999.1:45-48.

\section{AUTHOR'S BIOGRAPHY}

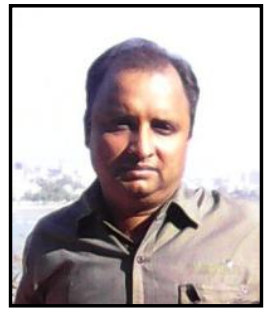

DR. Sunil J. Kulkarni, has completed his Masters in Chemical Engineering from Tatyasaheb Kore Institute of Engineering and Technology, Warananagar in 2006. $\mathrm{He}$ is currently pursuing his $\mathrm{phD}$ in chemical engineering. $\mathrm{He}$ is working as Assistant Professor in Chemical Engineering Department of Datta Meghe College of Engineering, Airoli, Navi Mumbai, India. The author has 16 years of experience in teaching and research. He has published 200 international review and research papers and presented 15 research papers in international conferences. His area of research includes adsorption, environmental engineering and catalysis. He is editorial board member of more than 25 international journals and reviewed many international papers.

Citation: Dr. Sunil Jayant Kulkarni, (2018). Petroleum and Refining Engineering-Brief Review on Few Key Aspects, International Journal of Petroleum and Petrochemical Engineering (IJPPE), 4(2), pp.17-21, DOI: http://dx.doi.org/10.20431/2454-7980.0402003

Copyright: (C) 2018 Dr. Sunil Jayant Kulkarni. This is an open-access article distributed under the terms of the Creative Commons Attribution License, which permits unrestricted use, distribution, and reproduction in any medium, provided the original author and source are credited 